УДК 621.865 .8

М.Н. Полищук

\title{
МЕТОД КОМПЕНСАЦИИ ПОТЕРЬ ПРОИЗВОДИТЕЛЬНОСТИ РОБОТОТЕХНОЛОГИЧЕСКИХ КОМПЛЕКСОВ
}

Аннотащия: Предложен метод компенсации потерь производительности робототехнологических комплексов, основанный на согласовании объемов межоперационных накопителей и цикловой производительности комплекса. Метод позволяет минимизировать объемы незавершенного производства и, тем самым, повысить фондоотдачу производственных площадей и роботизированных комплексов.

Ключевые слова: роботизированные комплексы, автоматизация технологических процессов, гибкие производственные системы

\section{Вступление}

Робототехнологические комплексы (РТК) являются составной частью гибких производственных систем (ГПС), которым, в отличие от жестких автоматизированных систем, свойственен дисбаланс операционного времени по отдельным рабочим позициям. Это объясняется необходимостью расширения номенклатуры выпускаемой продукции и различной степенью концентрации технологических операций. Для сглаживания аритмии выпуска продукции используются межоперационные накопители заготовок и полуфабрикатов обрабатываемых изделий. Согласование объема указанных накопителей и цикловой производительности позволяет уменьшить простой оборудования и повысить эффективность его эксплуатации.

\section{Анализ исследований и публикаций}

Расчет конструктивных и технологических параметров накопительных устройств РТК, например, таких как гравитационные лотки, бункеры, кассеты и т.п., изложены в работах $[1,2,3]$. Однако указанные методики в каждом конкретном случае определяются конструкцией направляющих, базирующих элементов, типом привода и не позволяют согласовать объемы накопителей $\mathrm{c}$ производительностью отдельных позиций автоматизированных комплексов. Поэтому задача сокращения внецикловых потерь их производительности вследствие объективной несинхронности работы технологических позиций является актуальной.

\footnotetext{
${ }^{\odot}$ М.Н. Полищук
} 


\section{Постановка задачи}

Необходимо найти квазиоптимальное соотношение объемов межоперационных накопителей и цикловой производительности РТК, а именно минимизировать дисбаланс операционного времени при условии обеспечения заданной производительности, определяемой лимитирующим по продолжительности операционным временем:

$$
\tau=q\left(t_{\max }-t_{\min }\right) / \sum_{i=1}^{q} t_{i} \Rightarrow \min \quad \text { при } t_{\max }-t_{\min } \triangleright 0 ; q \triangleright n, \mathrm{Q}=1 / t_{\max } ;
$$

где: $\tau$ - критерий дисбаланса операционного времени; $q-$ количество технологических позиций в РТК; $t_{\max }, t_{\min }, t_{i}-$ максимальное, минимальное и текущее время выполнения $i$-той технологической операции, соответственно; $n$ - минимальное количество рабочих позиций, необходимых для реализации технологического процесса в пределах данного РТК; $Q$ - цикловая производительность комплекса.

\section{Структура гибкой производственной системы}

На рис. 1 представлена общая структура ГПС, где модули М1, М2, $\mathrm{M} 3, . . \mathrm{MN}$, выполняют функцию накопления полуфабрикатов в объеме, необходимом для компенсации дисбаланса операционного времени технологического оборудования. Следует заметить, что указанная функция межоперационных накопителей не является единственной. Они также предназначены для компенсации внецикловых потерь производительности оборудования в условиях, так называемых, нештатных ситуаций, например, при отказах в работе того или иного технологического модуля. В этих случаях объем межоперационного накопителя следует определять с учетом времени устранения причин отказа. Однако в данной постановке задачи последнее не учитывается, поскольку решение задачи направлено именно на компенсацию потерь производительности, вызванных дисбалансом операционного времени, что в конечном итоге позволит минимизировать объемы незавершенного производства и, тем самым, повысить фондоотдачу производственных площадей и роботизированных комплексов. 


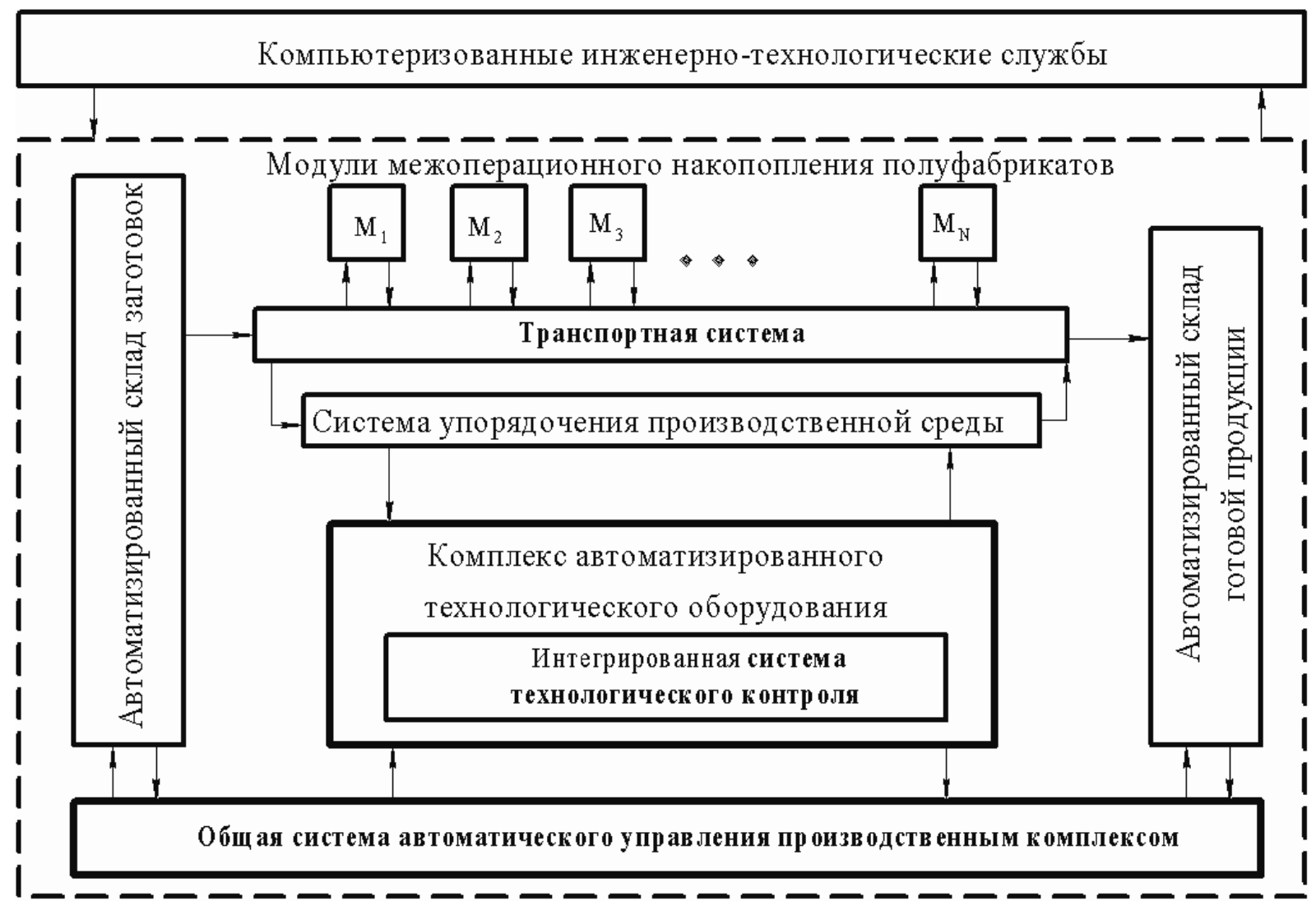

Рис. 1. Типовая структура ГПС

Из приведенной схемы ГПС, очевидно, что максимальный объем $G_{\max }$ каждого из накопителей (при последовательном их расположении согласно технологическому маршруту) будет определяться минимальным значением операционного времени:

$$
G_{\max }=E / t_{\min },
$$

где $E$ - максимальная емкость межоперационного накопителя в минутах, т.е. время, необходимое для сглаживания аритмичности работы смежных технологических позиций.

Определив из (1) минимальное значение технологического времени:

$$
t_{\min }=t_{\max }-\left(\tau \sum_{i=1}^{q} t_{i}\right) / q
$$

и подставивши его в (2), найдем необходимый запас полуфабрикатов в накопителях с учетом коэффициента дисбаланса операционного времени:

$$
G=E /\left[t_{\max }-\left(\tau \sum_{i=1}^{q} t_{i}\right) / q\right]=q E /\left(q t_{\max }-\tau \sum_{i=1}^{q} t_{i}\right),
$$

Поскольку цикловая производительность РТК определяется лимитирующей операцией (т.е. максимальной по значению операционного времени): 


$$
Q=1 / t_{\max }
$$

то аналогично изложенному выше, с учетом выражений (1) и (5), определим значение цикловой производительности РТК с учетом коэффициента дисбаланса операционного времени:

$$
Q=q /\left(\tau \sum_{i=1}^{q} t_{i}+q t_{\min }\right)
$$

Из сравнения зависимостей (4) и (6), очевидно, что при синхронной работе всех технологических модулей (что свойственно средствам автоматизации с жестким циклом, а не ГПС), т.е. когда отсутствует дисбаланс операционного времени, экстремальные значения объема межоперационного накопителя и производительности смежного технологического модуля составят:

$$
\text { при } \tau=0: G=E / t_{\max } ; Q=1 / t_{\min },
$$

что доказывает справедливость указанных выражений, поскольку именно при синхронной работе модулей автоматизированного комплекса имеет место минимальный объем межоперационных заделов при максимально возможной цикловой производительности.

Таким образом, при уменьшении дисбаланса операционного времени, когда $\tau \rightarrow 0$, объем полуфабрикатов в накопителях уменьшается (а значит, снижается и объем незавершенного производства), и напротив, производительность РТК стремиться к максимально возможному значению. Записавши выражения (4) и (6) в виде:

$$
\tau \sum_{i=1}^{q} t_{i} / q=t_{\max }-E / G ; \quad \tau \sum_{i=1}^{q} t_{i} / q=1 / Q-t_{\min },
$$

после преобразования получим формулу для вычисления согласованного с производительностью объема межоперационного накопителя:

$$
G^{o n m}=E /\left(t_{\max }+t_{\min }-1 / Q\right) \text {. }
$$

Разумеется, что при разработке технологического процесса следует стремиться к минимальному расхождению экстремальных значений операционного времени смежных технологических позиций. Однако, в условиях гибкого производства, характерной чертой которого является отсутствие жесткого ритма работы автоматического комплекса, всегда имеет место дисбаланс операционного времени. Последнее, как отмечено выше, является следствием расширенных технологических возможностей каждого РТК, входящего в ГПС. 
Построив графики зависимостей (4) и (6), показанных на рис. 2, в точках их пересечения находим согласованное значение коэффициента дисбаланса операционного времени, которое обеспечивает наилучшее соотношение цикловой производительности технологических модулей и емкости межоперационных накопителей. Предпочтительность такого значения емкости накопителей объясняется тем, что при этом минимизируется объем незавершенного производства, с одной стороны, и достигается максимально допустимая цикловая производительность РТк, образующих автоматизированный комплекс.

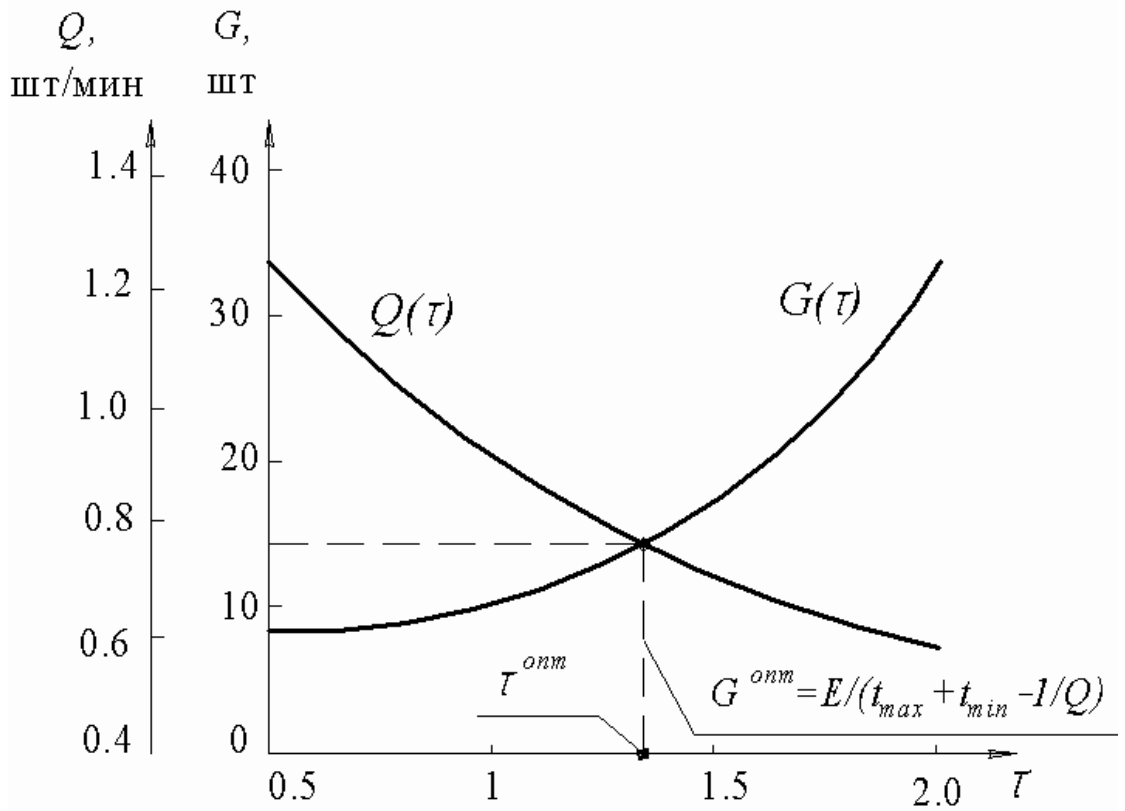

Рис. 2. Зависимости производительности комплекса и емкости накопителей от коэффициента дисбаланса операционного времени:

$$
\text { (при : } q=50 \text { ед.; } \mathrm{t}_{\min }=0,5 ; \mathrm{t}_{\max }=1,5 \text { (мин.); } \sum_{i=1}^{q} t_{i}=30 \text { мин.) }
$$

Проектирование межоперационных накопителей неразрывно связано также и с организацией технологического процесса на роботизированных участках. Так, выбор квазиоптимального соотношения объемов накопителей и производительности РТК необходимо рассматривать относительно двух случаев: 1) при производственной необходимости в увеличении годового выпуска продукции путем повышения производительности оборудования; 2) при отсутствии такой необходимости, когда уменьшение дисбаланса операционного времени дает возможность снизить объем незавершенного производства за счет минимизации емкости транзитных накопителей, а также снизить затраты на энергообеспечение. 
Для первого из указанных случаев рекомендуется дифференциация лимитирующих во времени технологических операций на отдельные, одновременно выполняемые технологические переходы, изменение структуры ГПС с разделением на отдельные участки и установкой между ними транзитных накопителей, увеличение идентичного оборудования, несмотря на дополнительные фондовые затраты.

Для второго из указанных случаев целесообразным будет концентрация технологических операций. Это дает возможность уменьшить количество основного оборудования за счет расширения технологических возможностей инструментальной и базовой оснастки. Рекомендуется накопление объектов производства непосредственно в рабочей зоне с целью обработки их партиями (что свойственно ГПС) и применение конвейерных накопителей асинхронного типа с различной скоростью перемещения между технологическими позициями.

\section{Выводы}

1. Предложенный метод компенсации потерь производительности РТК, основанный на обеспечении квазиоптимального соотношения цикловой производительности и объема межоперационных накопителей, позволяет уменьшить объем незавершенного производства и, тем самым, повысить фондоотдачу производственных площадей и оборудования.

2. Рассмотренный метод предоставляет возможность сглаживания аритмии технологических циклов РТК, входящих в ГПС, что, в свою очередь, повышает коэффициент технического использования основного производственного оборудования.

\section{ЛИТЕРАТУРА}

1. Гнучкі комп'ютеризовані системи: проектування, моделювання і управління: підручник / [авт. кол.: Л.С. Ямпольський, П.П. Мельничук, Б.Б.Самотокін, М.М.Поліщук, М.М. Ткач, К.Б. Остапченко, О.І. Лісовиченко]. - Житомир: ЖДТТ, 2005. - 680 с.

2. Ямпольский Л.С., Полищук М.Н., Оптимизация технологических процессов в гибких производственных системах. - К.: Техника, 1988. $-175 \mathrm{c}$.

3. Яхимович В.А. Транспортно-загрузочные и сборочные устройства и автоматы. - К.: Техника, 1974. - 144 с. 